\title{
A ORGANIZAÇÃO DE UMA RECEPÇÃO VIRTUAL DE CALOURAS COMO TENTATIVA DE EVITAR A EVASÃO FEMININA NA ESCOLA POLITÉCNICA DA UFBA
}

\author{
Moira Bastos Prates-moira.bastos@ufba.br \\ Universidade Federal da Bahia \\ R. Prof. Aristídes Novis, 2 - Federação \\ 40210630 - Salvador - Bahia \\ Juliane Grasiela de Carvalho Gomes-juliane.gomes@ufba.br \\ Universidade Federal da Bahia \\ R. Prof. Aristídes Novis, 2 - Federação \\ 40210630 - Salvador - Bahia \\ Gabrielle Desireé Cardoso de Souza-gabrielle.desiree@ufba.br \\ Universidade Federal da Bahia \\ R. Prof. Aristídes Novis, 2 - Federação \\ 40210630 - Salvador - Bahia
}

Resumo: Vista a diferença acentuada entre o número de mulheres e homens nas áreas de engenharia no Brasil, fez-se necessário formar um grupo responsável por criar um espaço de fala para mulheres inseridas em um ambiente majoritariamente masculino. Em meio a pandemia que assola o país surge também a preocupação com a evasão dos calouros das universidades públicas que tiveram as aulas interrompidas e a partir disso, a ciência de que essa evasão pode aumentar a diferença numérica entre os gêneros. Por isso, foi planejado, de forma inédita, um evento online que se atentou as causas de evasão presentes no modelo de abandono de Spady para evitar o agravamento da disparidade de gênero na área de engenharia.

Palavras-chave: Recepção de calouras. Contenção de evasão. Mulheres na engenharia.

\section{INTRODUÇÃO}

O ambiente acadêmico deveria ser um recorte que representasse, em todos os seus núcleos, a nossa sociedade, mas dentro de certas áreas isso não acontece. Segundo o IBGE, no Brasil, cerca de 51,8\% da população é composta por mulheres. Genericamente, esses números são refletidos nos cursos de graduação do Brasil, já que, segundo o Censo de Educação Superior de 2016, 57,2\% dos estudantes matriculados em cursos de graduação são mulheres. Contudo, quando paramos para analisar os cursos de engenharia os números sofrem grandes alterações. Também segundo o Censo de Educação Superior de 2016, dos estudantes de engenharia do país, somente $28,3 \%$ são mulheres.

Estima-se que na Universidade Federal da Bahia, 62,3\% dos estudantes de graduação são mulheres, o que é um número acima do percentual nacional, mas dentro da Escola Politécnica 
da UFBA o número de mulheres na graduação cai absurdamente, chegando a $26 \%$ do total de estudantes matriculados na escola.

Existem muitos motivos da diferença numérica entre os gêneros, o principal deles é o modelo de construção da sociedade brasileira, que é baseada no patriarcado. A repressão feminina e associação da figura da mulher apenas a áreas relacionadas com o cuidado humano ainda é um problema existente, mas a sociedade tem dado pequenos passos em direção a mudanças significativas.

A primeira escola de engenharia do país surgiu em 17 de dezembro de 1792, com a criação da Real Academia de Artilharia, Fortificação e Desenho (atual Escola Politécnica da UFRJ) no Rio de Janeiro. Na Bahia, em 14 de março de 1896, foi fundada a atual Escola Politécnica da UFBA (EPUFBA). Mesmo com as seculares escolas de engenharia do país, foi só em março de 1917 que a primeira mulher se formou em engenharia no Brasil.

Uma grande preocupação no ambiente universitário é a evasão, ou seja, a desistência de um curso levando à mudança para outro curso ou o abandono total da universidade. Essa saída precoce pode ocorrer por vários motivos diferentes sendo alguns deles; a situação financeira dos estudantes, a falta de preparo para a vida acadêmica, a falta de identificação com o curso no qual o estudante está matriculado, ou até o rendimento insatisfatório nas disciplinas cursadas. Esse problema afeta não só os discentes, mas também as instituições de ensino e a sociedade em geral por perder um futuro profissional. (TINTO, 1975).

Atualmente, o Brasil é assolado por uma pandemia que parou o mundo. E de forma não muito diferente, interrompeu o ensino presencial nas universidades públicas do país. Algumas das instituições de ensino tiveram a capacidade de se adaptar rapidamente às novas circunstâncias, oferecendo aulas online, mas esse não foi o caso da Universidade Federal da Bahia (UFBA), que por ter muitos estudantes em situação de vulnerabilidade, decidiu prezar ao máximo por não aumentar de nenhuma forma as desigualdades já existente na universidade e no Brasil.

Dia dois de março de 2020 foi iniciado o semestre letivo de 2020.1 na UFBA, duas semanas depois, o semestre foi interrompido por tempo indeterminado. Surgiu então, por parte do grupo Women In Engineering da Universidade Federal da Bahia (WIE UFBA), uma preocupação instantânea com as calouras do curso. É de conhecimento de todos a realidade quanto a evasão dos estudantes de engenharia e também da diferença quantitativa entre mulheres e homens quando tratamos de algo nesse espaço. Identificou-se então a necessidade de tomar alguma iniciativa que viesse a evitar o agravamento da disparidade entre mulheres e homens na Escola Politécnica através da possível evasão das calouras.

A pandemia foi uma situação inédita no século XXI, já que a última pandemia vivenciada pela humanidade foi a da Gripe Espanhola entre os anos de 1918 e 1920. Dessa forma, medidas inéditas também formam necessárias. $\mathrm{O}$ avanço da tecnologia, que ocorreu entre as duas pandemias, possibilitou uma série de medidas diferencias para minimização dos danos. Em relação à educação, em algumas instituições, aulas remotas foram adotadas, e assim, o instinto inicial do grupo, que até então tinha sua maior parte formada por graduandas e graduandos em Engenharia Elétrica, foi de entrar em contato com as calouras do mesmo curso.

Aos poucos, o contato foi se expandindo com estudantes de outros cursos e surgiu a ideia de realizar uma recepção de calouras online, um recorte de gênero para uma recepção de calouros que, até então, nunca havia ocorrido dentro da Universidade Federal da Bahia.

O evento, que foi organizado de modo a contemplar todos os cursos de Engenharia da Escola Politécnica da UFBA, teve o seu planejamento baseado nas dimensões do modelo de Spady para as causas da evasão. São elas: o Potencial Acadêmico que se refere a qualidade do ensino, nível da escola e desempenho (notas) do ensino médio; Congruência Normativa, que é 
conjunto de características da personalidade, valores culturais, atitudes em relação às demandas da IES, aspirações e expectativas quanto à carreira. Além das Relações estruturais - principais relações entre heterossexuais, envolvimento extracurricular e contato com o corpo docente; Integração Social - sentimento de pertencimento, relações interpessoais, percepção das normas existentes entre IES e estudantes; Satisfação, definida pelo autor como a percepção do aluno em relação à vivência como universitário; Desenvolvimento Intelectual, que trata da disposição para realizar as atividades do curso, capacidade de expansão de sua cultura intelectual, capacidade de pensar sistematicamente e criticamente e excelência percebida na realização dos trabalhos acadêmicos e, por fim, o Comprometimento Institucional, que é importância atribuída ao término do curso nessa ou em outra IES.

\section{CONHECENDO O WOMEN IN ENGINEERING UFBA}

Antes de tudo, faz-se necessário uma pequena revisão sobre o grupo ao qual a atividade esteve atrelada. O Instituto de Engenheiros Eletricistas e Eletrônicos, IEEE, é uma organização sem fins lucrativos a nível mundial que leva como missão promover o avanço tecnológico em prol da humanidade. Esta organização está presente nas universidades por meio dos Ramos Estudantis, grupos de alunos, membros e voluntários do IEEE que promovem atividades que se alinham com o objetivo da instituição.

O IEEE Women In Engineering é um grupo de afinidade, que surgiu por volta do ano de 1993, quando a Comissão de Atividades Técnicas do IEEE aprovou uma ação que encorajava a participação de mulheres em suas atividades.

O Ramo Estudantil IEEE UFBA existe desde 1983 e em 2009 foi fundado o grupo de afinidade Women In Engineering UFBA, por um grupo de voluntárias do Ramo que sentiam a necessidade de um espaço para dar voz às mulheres estudantes de engenharia. Desde então, o WIE UFBA trabalha com o objetivo, através de suas atividades, de incentivar e inspirar mulheres de dentro e de fora da universidade a ingressar ou permanecer nas áreas de engenharia e ciências exatas em geral.

\section{EVASÃO}

A evasão refere-se a saída do universitário por motivos diferentes da sua diplomação. Os dados do Fórum universitário da editora Pearson, em 2011, apontam que a taxa média de evasão no Brasil é de $22 \%$.

O abandono da graduação, por parte dos universitários, representa desperdícios sociais, acadêmicos e econômicos, tanto para as instituições, quanto para os alunos. E nas universidades públicas, que já sofrem com escassez de recurso, representa investimento público sem o retorno esperado pela sociedade. (LOBO et al., 2009).

A situação instaurada pela pandemia de Coronavírus fez com que as universidades suspendessem as atividades acadêmicas logo no início do ano letivo. Ainda não é possível prever os efeitos que a situação atual pode causar na educação brasileira, entretanto, alguns dados já apontam que mais de 250 mil universitários abandonaram ou trancaram os seus cursos nos meses de abril e maio. Na UFBA, ainda não é possível mensurar a evasão, uma vez que as atividades acadêmicas e administrativas estão suspensas, assim, os universitários não conseguem trancar seus cursos e não há forma de medir o abandono das atividades acadêmicas.

Ao estudar as razões que levam ao abandono do ensino superior, Spady e Tinto Vincent fazem analogia as teorias de Èmile Durkheim ao suicídio, com ressalva que a evasão é uma situação muito menos grave que a ação de tirar a própria vida. Spady e Tinto Vincent defendem 
que assim como no suicídio, o abandono do ensino superior tem mais chances de ocorrer quando o indivíduo não participa ou participa pouco do contexto social.

Spady destaca ainda que a motivação de homens e mulheres para abandonar a graduação pode ser diferente. Segundo ele, enquanto os homens se importam mais com o desempenho acadêmico medido por nota, as mulheres costumam se importar mais com o comprometimento institucional, ou seja, como se dá a sua relação com a universidade e seus membros.

\section{OBJETIVOS E JUSTIFICATIVA}

Tendo em vista, a situação ocasionada pelo coronavírus, o Modelo de abandono de Spady e o fato de que as novatas tiveram apenas duas semanas de aula, tempo insuficiente para formação de laços com seus colegas e a universidade, pensou-se numa recepção para que as calouras das engenharias pudessem se integrar com as suas veteranas, egressas e com a Escola Politécnica como um todo, uma vez que a evasão de mulheres nos cursos de engenharia representaria um grande impacto na já acentuada desigualdade numérica entre estudantes do sexo feminino e masculinos nos cursos de exatas e é missão do WIE promover ambientes que estimulem a entrada, permanência e formação nos cursos voltados a engenharia e tecnologia.

Além das calouras de engenharia, também foram convidadas alunas do BI (Bacharelado Interdisciplinar). O BI é um curso superior de formação interdisciplinar dividido em duas etapas. A primeira etapa é a de formação geral, comum aos cursos de BI (humanidades, ciência e tecnologia, artes e saúde). A segunda etapa é específica de acordo com a área que o aluno se matriculou. Após a finalização do curso, o egresso pode optar por seguir para o mercado de trabalho, ir para uma pós-graduação ou por ingressar em outro curso de graduação na própria UFBA.

As estudantes do BI de Ciência e Tecnologia (BI de C\&T) foram contempladas pela recepção de calouras, uma vez que após a conclusão do curso, grande parte procura ingressar em um dos cursos de engenharia da Escola Politécnica da UFBA.

Desta forma, para as alunas do BI, a recepção foi não só uma forma de integração com a universidade, mas também um meio de conhecer mais a fundo as engenharias, tornando mais simples a escolha de uma futura graduação. e evitando evasões futuras, causadas pela não identificação com o curso.

\section{PLANEJAMENTO}

O objetivo principal do evento era diminuir a distância existente entre as calouras e a universidade, já que durante o período de interrupção do semestre, muitas das atividades de pesquisa seguiram funcionando, assim como o Ramo IEEE e o WIE UFBA. Desta forma, apresentando o curso e todas as possibilidades dentro da universidade, as mais novas estudantes da UFBA poderiam, dentro do possível, desenvolver interesse ou até começar a participar de alguma atividade acadêmica.

Era necessário também ter apoio da Escola Politécnica, para que um representante oficial participasse do evento de forma a apresentar a escola possibilitando um contato das calouras com um membro da diretoria da EPUFBA.

Outra consideração importante foi feita com relação a necessidade de apresentar o perfil e competências de um egresso de qualquer um dos cursos de engenharia. Desta forma, verificouse a necessidade da participação de engenheiras já formadas.

Estabelecidas as prioridades, uma equipe de voluntárias e voluntários do WIE dividiram a organização do evento nas seguintes etapas: 
Listar os cursos de engenharia da Escola Politécnica da UFBA e buscar o contato das calouras através do colegiado ou do centro acadêmico de cada um dos cursos

A escola politécnica da UFBA possui, atualmente, 10 cursos de graduação em engenharia, são estes: Engenharia Elétrica, Engenharia de Controle e Automação de Processos, Engenharia Sanitária e Ambiental, Engenharia Civil, Engenharia Mecânica, Engenharia de Minas, Engenharia da Computação, Engenharia de Agrimensura e Cartográfica, Engenharia de Produção e Engenharia Química.

O contato foi estabelecido através de email e redes sociais. No total, foram recebidas 68 inscrições no evento. Sabendo que o número de inscritas não correspondia com o número de calouras da EPUFBA, o grupo se preocupou em deixar todo o evento registrado, para que quando possível, o restante das calouras tivesse acesso.

\section{Organizar a dinâmica do evento e a sua gravação}

Nesta etapa foram decididas como seriam divididas as salas de apresentação, onde cada engenharia seria alocada e como seria a dinâmica de gravação. Para a execução da recepção, foi escolhida a plataforma Google Meet, que além de ser intuitiva e realizar a gravação de maneira simples (para membros com conta institucional do IEEE), comportava a quantidade de convidadas do evento. $\mathrm{O}$ evento foi dividido em 4 salas, da seguinte forma:

- Sala principal: Onde houve a participação da diretora da Escola Politécnica da UFBA e da Ex-presidente do IEEE UFBA e do WIE UFBA, além do depoimento das engenheiras formadas.

- Sala I: Monitoria de Engenharia Elétrica, Engenharia de Computação e Engenharia de Controle e Automação de Processos.

- Sala II: Monitoria de Engenharia Química, Engenharia Sanitária e Ambiental e Engenharia de Agrimensura e Cartográfica.

- Sala III: Monitoria de Engenharia de Produção, Engenharia Civil, Engenharia de Minas e Engenharia Mecânica.

\section{Procurar a administração da EPUFBA para participação e apoio no evento}

Nesta etapa, a equipe organizadora entrou em contato diretamente com a diretoria da Escola Politécnica e a diretora se dispôs a participar do evento. Por ser uma recepção para as calouras, um ponto muito interessante é que, em um meio majoritariamente masculino, a diretora da EPUFBA, é uma mulher.

\section{Entrar em contato com egressas de cada um dos cursos}

As organizadoras e os organizadores procuraram mulheres formadas em cada um dos cursos de engenharia da UFBA para que elas dessem um depoimento sobre a vivência dentro da UFBA e a carreira na engenharia. Posteriormente, os depoimentos se tornaram uma série na Instagram TV (IGTV) do WIE UFBA para qualquer mulher que queira se inspirar com as histórias das engenheiras egressas da universidade.

\section{Definir bases para o conteúdo abordado por monitoras e palestrantes}

As monitoras receberam previamente um conjunto de tópicos que deveriam ser abordados em relação aos seus cursos, e entidades acadêmicas correlatas. Os assuntos abordados pelas veteranas aliados a apresentação da diretora da EPUFBA foram planejados em atenção as 
dimensões que levam a satisfação e comprometimento do universitário segundo a síntese do Modelo do processo de abandono de Spady (CRUZ, 2019).

Com exceção da dimensão Background familiar, todas as demais pautaram a recepção. Em especial a satisfação, que é definida na síntese como a "percepção do aluno em relação à vivência como universitário", integração social e o desenvolvimento intelectual.

A proposta da apresentação da diretora da Escola Politécnica era trazer a história e os valores da universidade, o perfil esperado da estudante de engenharia e funcionamento da instituição como um todo, atendendo as dimensões de congruência normativa, que se refere ao alinhamento de personalidade e valores, expectativas e aspirações das alunas, e relações estruturais no que tange o contato com o corpo docente.

As diversas atividades extracurriculares, entidades, programas de intercâmbio e projetos de pesquisa e extensão apresentadas em todas as etapas do evento buscavam, além da congruência normativa, dialogar com as dimensões de integração social e desenvolvimento intelectual, mostrando a capacidade de expansão do conhecimento que a universidade traz.

As monitoras também foram convidadas a falar sobre atividades que podem impulsionar o desempenho da aluna nos componentes curriculares, como monitoria, Programas de Educação Tutorial e o direito a horário de esclarecimento com o professor. Ao trazer esses pontos, o objetivo era mostrar formas de mitigar os impactos que deficiências no ensino médio pode ocasionar na dimensão chamada de potencial acadêmico, ou seja, a facilidade que o aluno pode encontrar baseada na qualidade das experiências escolares anteriores. Além de afetar diretamente a performance medida em nota, que também é uma das dimensões observadas.

Os vídeos de engenheiras formadas pela UFBA e atuantes profissionalmente visavam permitir que as novatas criassem expectativas favoráveis em relação a sua carreira e observassem a importância de terminar o curso e tivesse comprometimento com a instituição. Isso motiva as alunas a buscarem uma formação superior.

Por fim, um ponto não abordado na síntese, mas também ressaltado por Spady como motivo do abandono, é a questão socioeconômica. Condições financeiras desfavoráveis podem impedir o custeio dos estudos (SANTOS JUNIOR; REAL, 2017). Em relação a isso, destacase a quantidade significativa de alunos não oriundos da capital que estudam na UFBA e o perfil socioeconômico da instituição. Em resposta a isso, a primeira apresentação contemplou ações da universidade que auxiliam o estudante em relação a moradia, transporte, alimentação, entre outras ações promovidas pela Pró-Reitoria de Ações Afirmativas e Assistência Estudantil (PROAE). As atividades da universidade que oferecem bolsas também foram apresentadas, bem como, destacou-se a existência dos cursos noturnos, permitindo a realização de atividades de natureza remuneratória no período oposto.

\section{Elaborar um material de suporte para as calouras}

Uma das preocupações da equipe organizadora foi passar para as calouras todas as informações necessárias sobre a universidade, as oportunidades, programas de intercâmbio, projetos de extensão, iniciação científica, grupos de apoio às mulheres, serviço de saúde da universidade, atividades desportivas, além disso direcionar as jovens estudantes quanto aos conteúdos abordados nos dois primeiros anos de todas as engenharias, quando ocorre o que é conhecido como ciclo básico, o período da universidade onde são cursados os cálculos, as físicas e outras matérias em comum a maioria das engenharias, como desenho técnico, geometria analítica a a l e linear.

Desta forma, foi criado um manual com dicas sobre a universidade e redirecionamento para links importantes da instituição, como pode ser visto abaixo: 


\section{COBENGE COBENGE 2020 da ABENGE}

\section{"Os desafios para formar hoje o engenheiro do amanhã"}

Figura 1- Manual de dicas para calouras
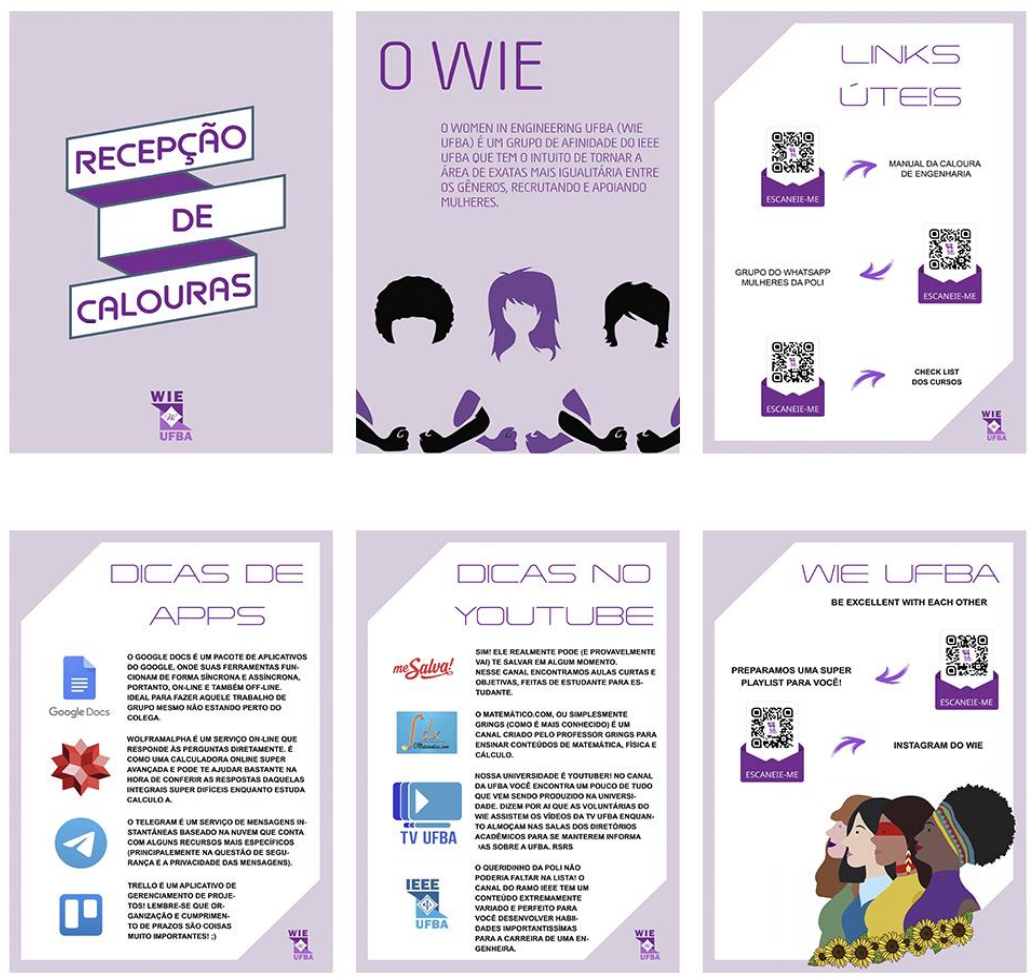

Fonte: Acervo do WIE UFBA

\section{Criar uma identidade visual e divulgar a inscrição no evento}

Para a divulgação do evento, foram criados banner para divulgação através das redes sociais e e-mail da UFBA (onde todos os estudantes estão cadastrados). Da mesma forma, ocorreu a divulgação do formulário de inscrição do evento.

\section{EXECUÇÃo}

\section{Sala Principal}

Na sala principal, houve a apresentação da ex-presidente do Ramo IEEE UFBA e do WIE UFBA, onde ela falou um pouco sobre cada uma das entidades, a missão dos grupos e a sua experiência dentro deles. Também nessa sala tivemos a apresentação da diretora da Escola Politécnica da UFBA onde ela apresentou a estrutura física da escola, os cursos, e orientou as meninas a participarem da universidade não somente dentro da sala de aula, mas nos eventos, entidades que cada curso possui, diretórios e centros acadêmicos além de guiá-las sobre como ter acesso aos respectivos coordenadores e professores.

Foi nessa sala também que houve a exibição de vídeos com depoimentos de engenheiras formadas na própria Escola Politécnica das diversas engenharias contando sobre sua formação, experiência e desafios no mercado de trabalho. 
Figura 2 - Mosaico com parte das participantes e palestrantes do evento

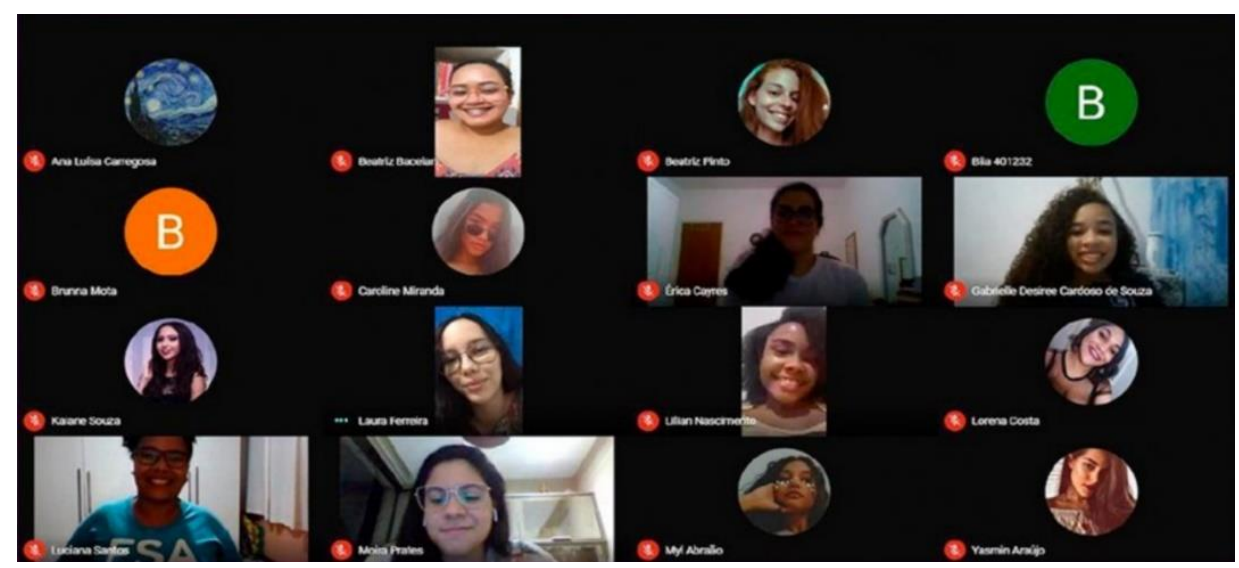

Fonte: Acervo do WIE UFBA

Figura 3 - Trecho da apresentação da Diretora da EPUFBA

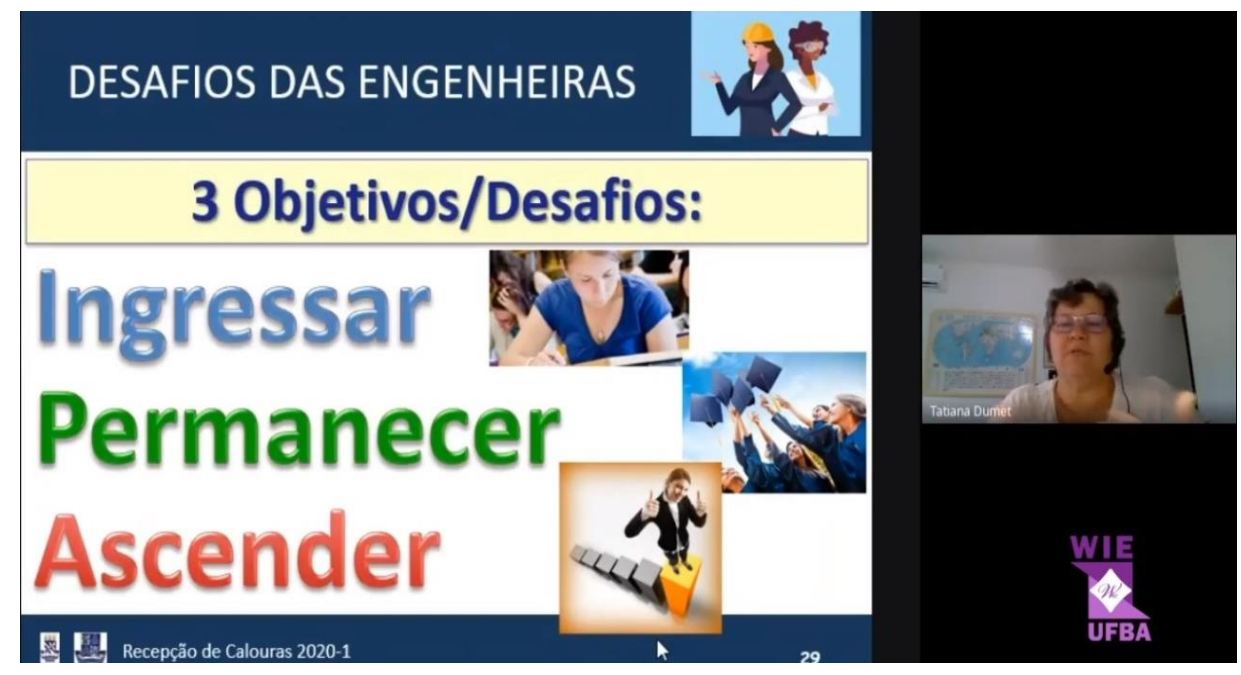

Fonte: Acervo do WIE UFBA

\section{Salas I, II e III}

Nestas salas, ocorreram as apresentações das monitoras dos cursos. Cada uma delas trouxe informações relevantes para auxiliar as calouras no processo de integração em seus respectivos cursos. Foi apresentada a grade curricular de cada um, as oportunidades de crescimento que se pode ter dentro da universidade como: iniciações científicas, Movimento Empresa Júnior (MEJ), grupos voltados às competições da $\mathrm{SAE}$, centros e diretórios acadêmicos, programas de intercâmbio, áreas de atuação de cada engenharia, além de dicas sobre como direcionar seu curso para a área escolhida. Cada monitora compartilhou também um pouco da sua experiência pessoal na vida acadêmica. 
Figura 4 - Exemplo de apresentação de curso

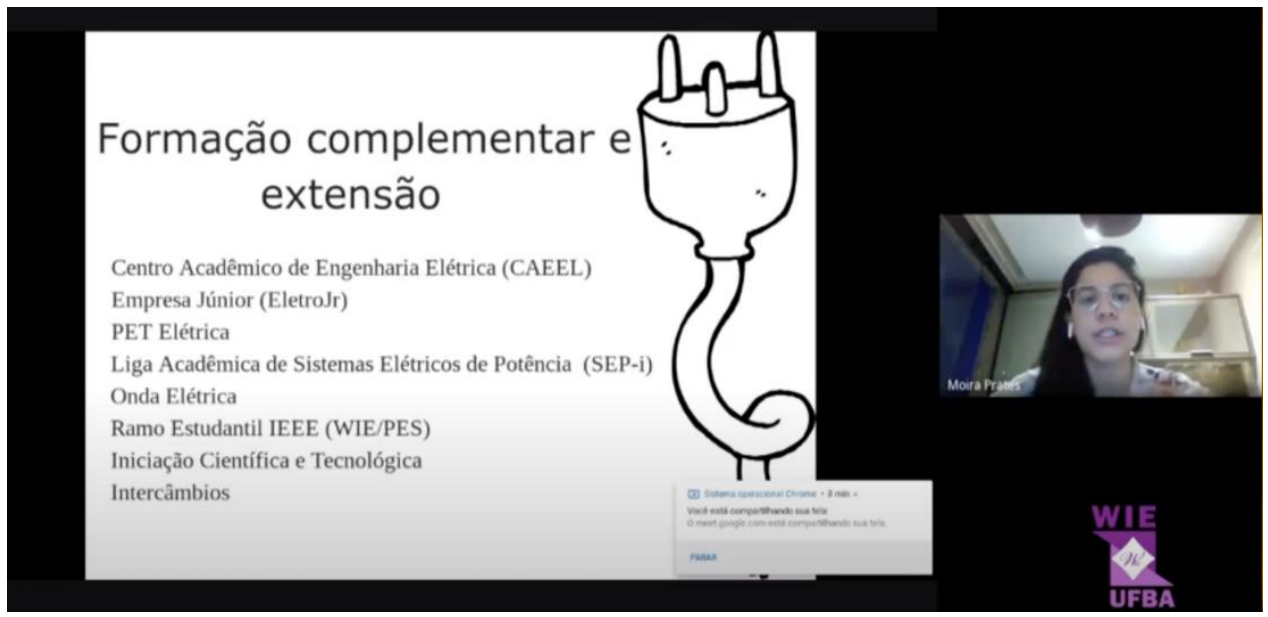

Fonte: Acervo do WIE UFBA

\section{CONSIDERAÇÕES FINAIS}

A recepção de calouras recebeu 68 inscrições, e atingiu até o mês de julho de 2020 aproximadamente 150 visualizações no YouTube (onde o evento foi publicado na íntegra), além de contar com 10 veteranas, a presença da diretora da EPUFBA e 5 participantes do WIE na organização.

A disponibilização dos vídeos num canal aberto permitiu que as calouras que não participaram ao vivo tivessem acesso ao conteúdo. Além disso, futuras ingressantes e aspirantes aos diversos cursos de engenharia poderão esclarecer suas dúvidas e fazer uma melhor escolha, contribuindo com uma possível diminuição no número de evasões futuras.

Os vídeos das profissionais egressas de UFBA deram origem a uma série no Instagram TV, chamada "Ser mulher na engenharia", que serve de inspiração para meninas e mulheres que almejam seguir na área. Até a publicação do presente artigo, a série contava com aproximadamente 1500 visualizações.

Foi realizada uma pesquisa com intuito de avaliar o impacto do evento no início da vida acadêmica das participantes. Foram observados pontos como ingresso e o possível engajamento nas atividades apresentadas, percepção da universidade e inserção no meio acadêmico, motivação e a influência do evento nesses fatores.

Entre as respostas destacam-se:

"Ao entender o que é o WIE, eu fiquei fascinada. Encontrei uma forma de estar em contato com a faculdade mesmo nesse período de distanciamento. Eu estava um tanto desmotivada em relação a algumas coisas, um tanto inerte em relação a outras, mas a recepção e a possibilidade de ser uma voluntária acenderam uma faísca em mim. Era o que eu precisava."

"[...] estava bastante insegura por conta de ser um meio bastante machista, a recepção foi importante pra perceber que não estou sozinha e que há mulheres incríveis pra mudar essa realidade e fortalecer outras pessoas."

Vale ressaltar que um indicador quantitativo da efetividade da recepção na tentativa de evitar a evasão das jovens estudantes só poderá ser constatada com um acompanhamento 
contínuo das mesmas. Acompanhamento este, que só poderá ser feito após o retorno das atividades regulares da universidade.

\section{REFERÊNCIAS}

CRUZ, Uendel Anunciação da. Evasão de discentes: um estudo na Universidade Federal da Bahia.

LOBO, Roberto Leal; FILHO, Silva, LOBO, Maria Beatriz - Evasão no Ensino Superior: Causas e Remédios - Junho, 2009. Disponível em: http://robertolobo.com.br/index.php/2009/06/evasao-no-ensino-superior-causas-e-remedios/ Acesso em: 20 jul. 2020.

PIMENTEL, A.; RUBIM, A. A.; BASTOS, A. V.; EMBIRUÇU, M.; MARINHO, M.; NERY, M.; PONTES, M.; FILHO, N. de A. Disponível em:https://ufba.br/sites/portal.ufba.br/files/implant_reuni.pdf. Acesso em: 21 jul. 2020.

SILVA JÚNIOR, A. S.; FRANCISCO JÚNIOR, W. E.; SILVA, J. C.; SILVA, J. M.. Repensando a evasão escolar: uma análise sobre o direito à educação no contexto amazônico. Holos, v. 2, p. 199-213, 2017.

SPADY, Willian G. Dropouts from higher education: an interdisciplinary review and synthesis. Interchange, v. 1, p. 64-85, 1970.

TINTO, Vincent; CULLEN, John. Dropout in higher education: A review and theoretical synthesis of recent research. Office of Education (DHEW), Washington, D.C. Office of Planning, Budgeting, and Evaluation, 1973.

VITELLI, Ricardo Ferreira; FRITSCH, Rosangela. Evasão escolar na educação superior: de que indicador estamos falando?. Estudos em Avaliação Educacional, v. 27, n. 66, p. 908-937, 2016.

. Dropouts from higher education: toward an empirical model.

Interchange, v. 2, issue 3, p.38-62, set. 1971.

\section{ORGANIZING A VIRTUAL FRESHMAN RECEPTION AS AN ATTEMPT TO PREVENT FEMALE EVASION AT THE POLYTECHNIC SCHOOL FROM THE FEDERAL UNIVERSITY OF BAHIA}

Abstract: From the certainty of the difference between the numbers of women and men around engineering fields in Brazil, it was necessary to create a group responsible for creating a safe space for women inserted in a mostly male environment. During the pandemic that smashed the country, a concern about the evasion in public universities that had the classes interrupted and the knowledge that this evasion can increase the numerical difference between genders, an event without precedents was planned to look for the causes of evasion present in Spady's model of abandonment in a way to avoid turning the gender gap worse inside of the engineering area. Keywords: Freshman reception. Evasion control. Women In Engineering. 